\title{
Residents' Attitudes Toward Street Trees in the UK and U.S. Communities
}

\author{
Herbert Schroeder, John Flannigan, and Richard Coles
}

\begin{abstract}
Research on residents' attitudes has shown that street trees are highly valued elements of the urban environment and that their benefits far outweigh their annoyances. Much of this research was done in communities in the United States, and it is uncertain whether the findings can be generalized to other communities or countries. We compared residents' opinions of street trees, perceptions of the benefits and annoyances trees provide, and preferences for tree size, shape, and growth rate between three communities in the United States and the United Kingdom. Overall, opinions of nearby street trees were positive and did not differ between the two UK communities and the U.S. community. Respondents in the UK communities rated annoyances as more serious, shade as less of a benefit, and physical benefits as more significant than did the residents of the U.S. community. Respondents in the two UK communities also preferred smaller trees with slower growth rates. Although these comparisons cannot be used to make inferences about differences between the entire United Kingdom and United States, they do suggest some specific ways in which community characteristics such as climate and proximity of trees to houses may contribute to variation in attitudes toward trees.
\end{abstract}

Key Words. Attitudes; benefits; residents; street trees; United Kingdom; United States.

The perceptions and attitudes of urban residents regarding street trees and vegetation in their communities have been well researched using visual simulation methods (Kalmbach and Kielbaso 1979; Schroeder and Cannon 1983; Sheets and Manzer 1991; Sommer et al. 1993b) and questionnaires asking residents about street trees in front of their homes (Sommer et al. 1989, 1990, 1993a; Schroeder and Ruffolo 1996). These studies have consistently shown that urban residents have a very positive view of trees, and that the annoyances of trees are outweighed by the benefits they provide. Most of these studies, however, have focused on specific cities or towns in North America, and researchers have cautioned against assuming that results from one study will generalize to other communities, cultures, and climatic zones.

In this article, we present an initial attempt to compare attitudes toward street trees between residents of selected communities in the United Kingdom and the United States. We combined data from a new survey of two communities in southwest England (Flannigan 2005) with data from an earlier study in a midwestern U.S. community (Schroeder and Ruffolo 1996) to explore how opinions of street trees and perceptions of the benefits and annoyances of trees vary across residents from communities located in different countries.

Concerns over the generalizability of research on attitudes toward street trees seem well founded in light of the few studies that have examined tree preferences outside the United States. For example, Williams (2002) discovered a greater appreciation for medium-sized trees in Australia as compared with the larger street trees preferred in the United States (Kalmbach and Kielbaso 1979; Schroeder and Cannon 1983). Fraser and Kenney (2000) found that Canadian residents with cultural backgrounds from different parts of the world had dramatically different preferences for the presence, size, and kinds of trees near their homes. In Scotland, Hitchmough and Bonugli (1997) found little support for street tree planting among residents of treeless streets, suggesting that the shade-casting role played by trees is appreciated more in sunnier locations such as the midwestern United States than in cooler, less sunny locations like the northern United Kingdom.

General arboricultural texts in the United Kingdom tend to echo Hitchmough and Bonugli's (1997) negative findings. Eminent UK arborists have described the "I love trees but ..." phenomenon. Giles Biddle (quoted in Clouston and Stansfield 1981, p. 17), for example, has stated that, "Perhaps one of the most commonly heard cries is 'I like trees, but not in front of my house." Peter Annett (quoted in Baker 1984, p. 46) adds, "How often have we heard 'I do not like trees because ....," whereas Derek Patch (quoted in Horticulture Week 1994, p. 11) has described how "Street trees are often unloved by the public ...." Dobson and Patch $(1997$, p. 1) 
developed this theme further, characterizing the public's attitude as "I love trees, but ... not-in-my-back-yard."

Solihull Metropolitan Borough Council's Tree Strategy expresses the equally negative view that "Those very same trees that make Solihull a pleasant town to live and work are, for many residents, a source of frustration" (Anon 2003, p. 7). As another example, after someone had secretly planted trees in residents' front gardens, a local authority tree officer was quoted in a national newspaper as saying, "It's refreshing to see someone planting trees rather than what we all too often see, which is people wanting to take them out" (Daily Mirror 2004). Such views appear to have been long held by professionals in the United Kingdom. An article from over 35 years ago states, "Let it be recognised that many urban trees are too large for their positions ... many often cause inconvenience to those against whose property they are situated" (Riseley 1969, p. 195).

Do residents indeed have a lower opinion of street trees in the United Kingdom than in the United States? Despite the negative reports from arborists, research (e.g., Kaplan and Kaplan 1989) suggests that people's positive responses to vegetation are the result of underlying perceptual and cognitive factors that apply to human beings in general. Several researchers (e.g., Heerwagen and Orians 1993) have hypothesized that evolutionary factors common to all humans create an inborn affinity for nature, particularly for the kind of environments in which humans evolved. Supporting this view, Sommer and Summit (1995, 1996), Sommer (1997), and Summit and Sommer (1999), found similar preferences across diverse international communities for tree shapes resembling those in the African savanna.

Moreover, the existence of strong legal tree protection measures (Anon 1990) and the annual planting of one million trees during National Tree Week suggest that trees are in fact valued in the United Kingdom. O'Brien and Claridge (2002) and Coles and Caserio (2004) describe strong support for urban and rural woodlands and trees in the United Kingdom. One study about the public's attitude to the environment and quality of life in the United Kingdom found that the loss of trees and hedgerows was becoming a growing cause for concern, rising from $17 \%$ of respondents in 1986 to $46 \%$ in 2001 (DEFRA 2002). Finally, the experience of one author of this article, while working as a local authority tree manager in the United Kingdom, strongly suggests that public support for trees exists.

The emphasis on negative public response to trees described in the UK professional literature might indicate that people who genuinely dislike living near trees are more likely to volunteer their opinions in the form of complaints to the local authority, whereas residents who hold less negative views may remain silent unless their opinions are actively sought out. It may also reflect an asymmetry in the impacts of benefits and annoyances on community residents. That is, the aesthetic and other benefits of a tree in front of a person's home accrue not only to that person, but also to their neighbors. The annoyances of the tree (fallen leaves, shaded garden, and damaged pavement) on the other hand are more likely to impact the property owner exclusively. Thus, a person might want to be rid of the annoyances from the particular tree in front of their own home while still appreciating the benefits of trees in the neighborhood at large. This would be consistent with the sentiment of "I like trees, but not in front of my house" reported previously. In any case, it is clear that more in-depth investigations of UK residents' attitudes toward street trees are needed to understand the actual impacts of the urban forest-both positive and negative-on residents. Such knowledge could be considered crucial if the resource is to be managed optimally.

As a first step toward obtaining this knowledge, Flannigan (2005) surveyed two communities in southwest England using the methodology of Sommer et al. (1989). This survey methodology was first developed in California cities and was later applied to a Chicago suburb by Schroeder and Ruffolo (1996). It provides a detailed assessment of residents' opinions and perceptions of both positive and negative features of the street trees immediately outside their homes. Flannigan's study established that, with suitable modifications, Sommer's survey method could be adapted to work with residents of the United Kingdom. In this article, we use the data from Flannigan's surveys along with that from Schroeder and Ruffolo's earlier study to take a first look at similarities and differences in attitudes toward street trees between residents of communities in the United Kingdom and the United States.

\section{SURVEY METHOD}

Flannigan (2005) surveyed the communities of North Somerset and Torbay in southwest England in 2003 using a modified version of the questionnaire that Schroeder and Ruffolo (1996) had used in the Chicago suburb of Downers Grove in 1988 and 1990. In all three communities, respondents were asked to rate their overall satisfaction with a specific street tree directly in front of their home, the significance of various benefits and annoyances associated with that tree, and their satisfaction with the size, shape, and growth rate of the tree. Survey forms were distributed by mail along with a cover letter explaining the purpose of the survey and a prepaid envelope for returning the survey.

The Downers Grove questionnaire was modified for use in Flannigan's study. A few questions that were not relevant to North Somerset and Torbay were removed, for example, questions about birds, squirrels, and bees being attracted to the tree (a common occurrence in Downers Grove but not in North Somerset and Torbay). Some more specific questions were added regarding problems that were of particular concern to the UK communities, for example, root damage (a significant liability issue in the United Kingdom) and shade- 
related annoyances (as a result of the United Kingdom's cloudier climate). The precise wording and spelling of some items were also changed to accord with British use. For example, where Schroeder and Ruffolo's survey referred to "yards," the North Somerset/Torbay survey said "gardens."

In both the original Downers Grove survey and the more recent survey of North Somerset and Torbay, the households to be surveyed were selected in consultation with the local tree management authority to address their information needs. In Downers Grove, the survey was mailed to 662 households selected by the village forester to represent eight species of street trees that he wanted to evaluate. In North Somerset, where almost all streets are characterized by pollarded trees, a random sample of $20 \%$ of streets was selected. The survey was mailed to all 119 residents on those 16 streets with a pollarded tree outside their home. In Torbay, two distinct groups of residents were surveyed. The survey was posted to all 22 properties in the district adjacent to regularly pollarded street trees to allow a comparison with attitudes toward the pollarded trees in North Somerset. Attitudes toward pollarded trees were of particular interest because of the prevalence of this management technique in the United Kingdom and the dramatic effect it has on the appearance of a tree. In addition, the Torbay survey was sent to all 71 residents of two streets which, according to the Torbay Arboricultural Manager, were characterized by residents' unhappiness with their nonpollarded, larger street trees. Thus, the individual surveys are not statistically random samples of their respective communities, but represent groups of residents who were of particular interest for management and research.

The evaluated trees in Downers Grove were typically located between the paved sidewalk and the street with an open lawn separating the tree from the house (Figure 1). The homes surveyed in North Somerset and Torbay, by contrast, mostly had enclosed front gardens. These were generally smaller than the front lawns in Downers Grove so that the evaluated trees were situated closer to people's houses (Figure 2).

Despite the modifications to the survey questionnaire, most of the questions on Flannigan's survey were substantially the same as on Schroeder and Ruffolo's. We combined the corresponding survey responses from the three communities to create a single data set, which we used to compare responses from North Somerset and Torbay with those from Downers Grove. (For survey items on which the wordings varied between the surveys, the British wordings are used in the presentation of results subsequently.) It should be noted that because the respondents of these surveys were not randomly sampled from their respective nations, the results of these comparisons do not necessarily correspond to general differences between the populations of the United Kingdom and the United States.

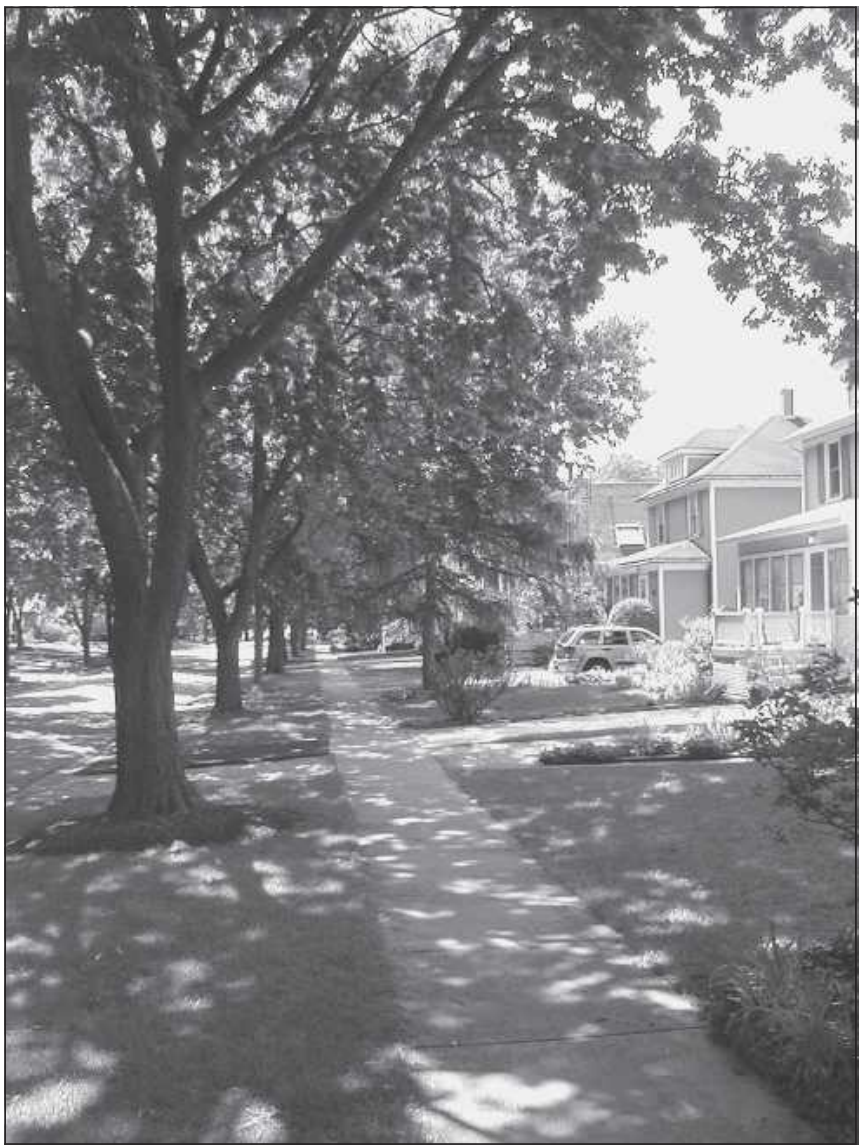

Figure 1. Street trees in Downers Grove, Illinois, U.S.

\section{RESULTS}

\section{Response Rates}

The overall response rate for the North Somerset/Torbay survey was $61 \%$, resulting in 130 usable surveys. The response rate for the earlier Downers Grove survey was 46\% with 307 usable surveys. These response rates are reasonably high given that no follow-up mailings or reminder cards were sent.

\section{Demographic Information}

Both the Downers Grove and the North Somerset/Torbay survey respondents were almost equally divided between men and women. Slightly more of the respondents were female in the North Somerset/Torbay survey (55\%) than in the Downers Grove survey (50\%), but this difference was not statistically significant. The respondents in the North Somerset/ Torbay survey were significantly older than their American counterparts. In the Downers Grove survey, $47 \%$ of participants were under 40 and $37 \%$ were over 50 as compared with $14 \%$ under 40 and $64 \%$ over 50 in the North Somerset/Torbay survey. A large majority of respondents owned their own homes in both North Somerset/Torbay (94\%) and Downers Grove (97\%). 


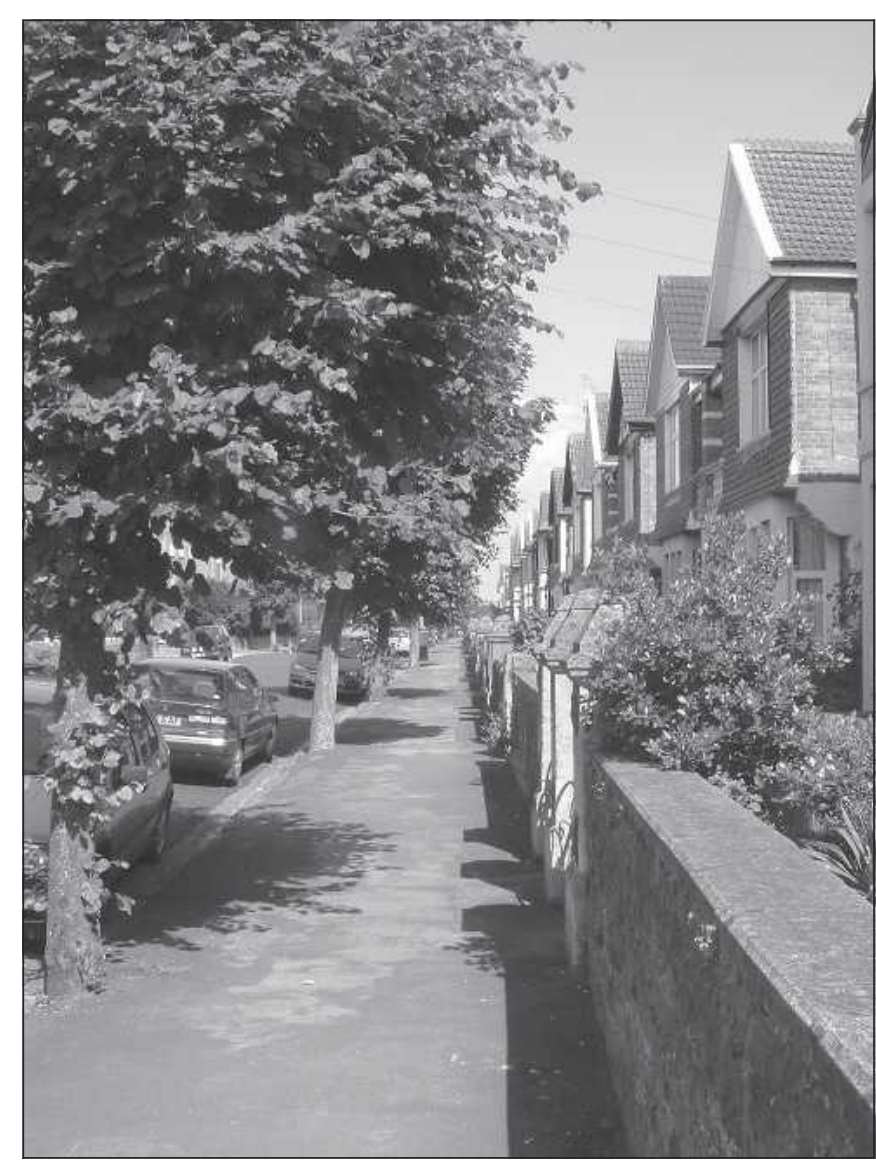

Figure 2. Pollarded street trees in North Somerset, UK.

Although differences between the educational systems in the United States and Britain make a precise comparison difficult, the educational levels of the two groups did appear to be roughly comparable. A high school diploma in the United States, usually obtained at age 17 or 18 , corresponds approximately to the GCSE, CSE, and O levels in England, which are attained at age 16. In the Downers Grove survey, $84 \%$ of respondents had completed this level and gone on to at least some additional education in college or technical school compared with $70 \%$ in the North Somerset/Torbay survey. Graduate school in the United States is equivalent to postgraduate education in the United Kingdom. In the Downers Grove survey, $30 \%$ had at least some education at this higher level compared with $26 \%$ in the North Somerset/ Torbay survey.

Income levels are also difficult to compare between the Downers Grove and the North Somerset/Torbay surveys as a result of inflation and the fluctuating exchange rate between the two countries during the interval of years between the Downers Grove and the North Somerset/Torbay surveys. In addition, there was a high proportion of nonresponses to the income question in both surveys $(40 \%$ in the Downers Grove survey and $70 \%$ in the North Somerset/Torbay survey).
Given these factors, a meaningful comparison of annual income between the Downers Grove and North Somerset/ Torbay respondents did not appear possible. All of the areas that were surveyed, however, could generally be characterized as middle-income neighborhoods.

Although we did not ask respondents to indicate their race, census data for the three communities in 2000 show that $90 \%$ of the population in Downers Grove and $99 \%$ in both North Somerset and Torbay were white, making it likely that most of the respondents in both surveys were white.

\section{Respondents' Evaluations of Street Trees}

A comparison of responses at the level of individual tree species between the North Somerset/Torbay and the Downers Grove surveys did not seem feasible because there were not enough tree species in common between the two surveys and because differences in visual form between species in the North Somerset/Torbay survey were obscured by the pollarding of trees. (None of the trees in the Downers Grove survey were pollarded.) The analysis therefore focused on differences in responses to corresponding questions between the Downers Grove and the North Somerset/Torbay surveys averaged over all tree species.

\section{Overall Opinion}

Respondents in both surveys had a high overall opinion of the tree outside their home (Table 1). A large majority of respondents rated their tree as "good," "very good," or "excellent." A Mann-Whitney U-test (Hays 1973) revealed no significant difference in overall opinion between the Downers Grove and North Somerset/Torbay surveys $(P=0.770)$.

\section{Benefits and Annoyances}

Residents were asked to rate the degree to which they received various benefits and annoyances from the tree outside their home using a four-point scale from "none" to "major." Figure 3 compares the mean ratings of tree benefits in the North Somerset/Torbay and the Downers Grove surveys. Respondents in both surveys gave high ratings to "pleasing to the eye," "enhances look of garden and home," and "brings nature closer." Two of the lowest rated benefits were "cools home in summer" and "flowers on tree."

Table 1. Respondent's overall opinion of the tree in front of their home.

\begin{tabular}{lccrrr}
\hline & \multicolumn{2}{c}{ North Somerset/Torbay } & & \multicolumn{2}{c}{ Downers Grove } \\
\cline { 2 - 3 } Opinion & $\mathrm{N}$ & & & $\mathrm{N}$ & $\%$ \\
\hline Very poor & 9 & 7 & & 11 & 4 \\
Poor & 6 & 5 & & 24 & 8 \\
Good & 38 & 30 & & 102 & 35 \\
Very good & 45 & 36 & & 89 & 30 \\
Excellent & 27 & 22 & & 67 & 23 \\
\hline
\end{tabular}




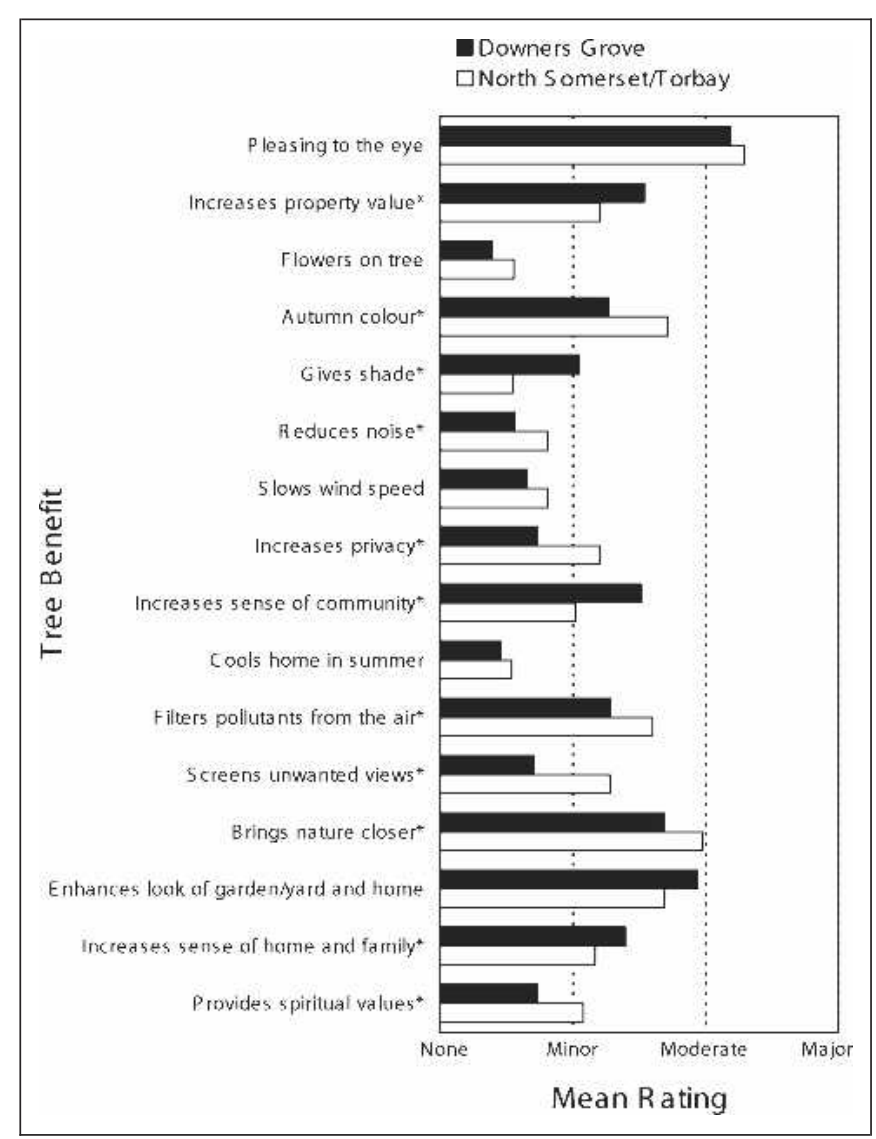

Figure 3. Mean rating of street tree benefits. (An asterisk following a benefit indicates that the Kruskal-Wallis test for the difference between Downers Grove and North Somerset/Torbay is significant at $P<0.05$.)

Respondents in the North Somerset/Torbay survey rated autumn color, noise reduction, increased privacy, filtering air pollutants, screening unwanted views, bringing nature closer, and spiritual values significantly higher as benefits than respondents in the Downers Grove survey. Increased property value, shade, sense of community, and sense of home and family were given significantly higher ratings in the Downers Grove survey.

Figure 4 compares the mean ratings for tree annoyances for the North Somerset/Torbay and Downers Grove surveys. The annoyances received from trees were, in general, rated as less prominent than the benefits in both surveys. Fallen leaves in autumn and general debris were rated as two of the worst annoyances in both surveys. All of the annoyances were rated as significantly more important in the North Somerset/Torbay survey than in the Downers Grove survey.

To further identify the pattern of differences between the North Somerset/Torbay and the Downers Grove surveys, we performed a principal components analysis of benefit and annoyance ratings on the combined set of surveys from both countries. Principal components analysis is a statistical technique for describing the pattern of variation in a large set of variables in terms of a smaller set of categories or factors based on the observed intercorrelations between the variables (Jackson 1991). Our analysis parallels Sommer and Sommer's (1989) principal components analysis of street tree annoyances and benefits in California.

We included six factors in our final analysis. Five of these factors had eigen values greater than 1 , which is the customary criterion for inclusion of a factor in the solution (Kaiser 1960). The sixth factor had an eigen value slightly less than 1 , but we chose to retain it in the solution because it improved the interpretability of the factor structure. To aid in interpreting the factors, the six-factor solution was subjected to a varimax rotation. The rotated factor matrix is shown in Table 2 .

Three of the six factors $(2,3$, and 6$)$ define groupings of related benefits, two factors ( 1 and 4$)$ define groupings of annoyances, and one factor (5) includes both a benefit and an annoyance. The headings at the tops of the columns in Table 2 represent our attempt to characterize the benefits and/or annoyances that load on the factor in that column.

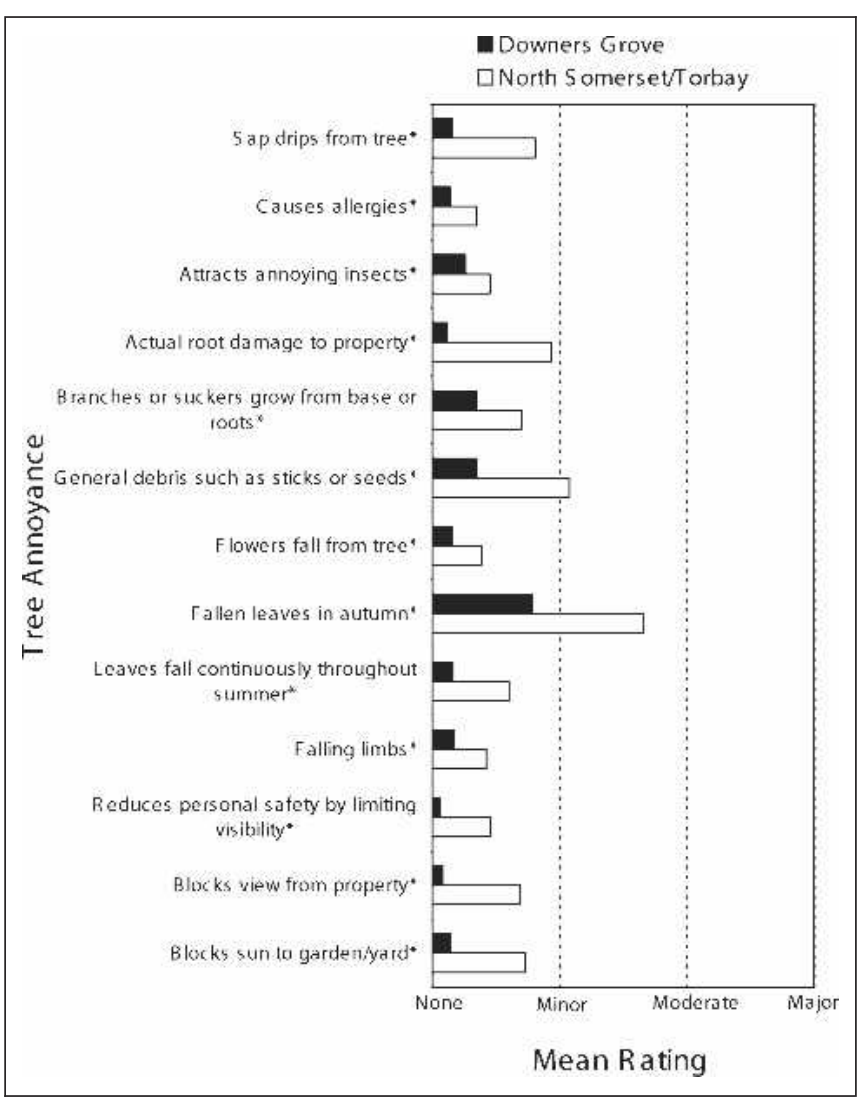

Figure 4. Mean rating of street tree annoyances. (An asterisk following an annoyance indicates that the KruskalWallis test for the difference between Downers Grove and North Somerset/Torbay is significant at $P<0.05$.) 
Table 2. Varimax rotated factor loadings of street tree benefits and annoyances.*

\begin{tabular}{|c|c|c|c|c|c|c|}
\hline & \multicolumn{6}{|c|}{ Factors } \\
\hline & $\begin{array}{l}\text { 1. General } \\
\text { annoyances }\end{array}$ & $\begin{array}{l}\text { 2. Intangible } \\
\text { benefits }\end{array}$ & $\begin{array}{l}\text { 3. Physical } \\
\text { benefits }\end{array}$ & $\begin{array}{l}\text { 4. Insects and } \\
\text { exudation }\end{array}$ & $\begin{array}{l}\text { 5. Seasonal } \\
\text { aesthetics }\end{array}$ & 6. Shade \\
\hline \multicolumn{7}{|l|}{ Benefits } \\
\hline Enhances look of garden and home & - & 0.832 & - & - & - & - \\
\hline Increases sense of home and family & - & 0.804 & - & - & - & - \\
\hline Brings nature closer & - & 0.795 & - & - & - & - \\
\hline Increases property value & - & 0.768 & - & - & - & - \\
\hline Pleasing to the eye & - & 0.719 & - & - & - & - \\
\hline Increases sense of community & - & 0.712 & - & - & - & - \\
\hline Provides spiritual values & - & 0.629 & - & - & - & - \\
\hline Filters pollutants from the air & - & 0.515 & $(0.493)$ & - & - & - \\
\hline Autumn color & - & 0.511 & - & - & $(0.416)$ & - \\
\hline Increases privacy & - & - & 0.820 & - & - & - \\
\hline Reduces noise & - & - & 0.791 & - & - & - \\
\hline Slows wind speed & - & - & 0.779 & - & - & - \\
\hline Screens unwanted views & - & - & 0.735 & - & - & - \\
\hline Cools home in summer & - & - & 0.615 & - & - & $(0.495)$ \\
\hline Flowers on tree & - & - & - & - & 0.780 & - \\
\hline Gives shade & - & - & - & - & - & 0.676 \\
\hline \multicolumn{7}{|l|}{ Annoyances } \\
\hline Actual root damage to property & 0.753 & - & - & - & - & - \\
\hline Leaves fall continuously throughout summer & 0.736 & - & - & - & - & - \\
\hline Falling limbs & 0.735 & - & - & - & - & - \\
\hline General debris such as sticks or seeds & 0.731 & - & - & - & - & - \\
\hline Fallen leaves in autumn & 0.723 & - & - & - & - & - \\
\hline Reduces personal safety by limiting visibility & 0.682 & - & - & - & - & - \\
\hline Blocks sun to garden & 0.680 & - & - & - & - & - \\
\hline Blocks view from property & 0.677 & - & - & - & - & - \\
\hline Flowers fall from tree & 0.572 & - & - & - & $(0.515)$ & - \\
\hline Branches or suckers grow from base or roots & 0.513 & - & - & - & - & - \\
\hline Sap drips from tree & $(0.434)$ & - & - & 0.588 & - & - \\
\hline Causes allergies & - & - & - & 0.783 & - & - \\
\hline Attracts annoying insects & - & - & - & 0.748 & - & - \\
\hline
\end{tabular}

*Only factor loadings greater than 0.40 are shown. When an item loads on more than one factor, the smaller of the loadings is shown in parentheses.

The first factor (general annoyances) accounts for $18.0 \%$ of the variance in benefit and annoyance ratings and encompasses most of the annoyance items on the survey. This factor includes physical damage from roots, falling debris of all kinds, branches or suckers, and obstructed views and sunlight. Dripping sap is also weakly associated with this factor.

The second factor (intangible benefits) accounts for 17.6\% of the variance. The items that load on this factor include a variety of subjective and aesthetic benefits plus the economic benefit of increased property value. The fact that property value is associated with this factor suggests that the respondents may see housing prices as significantly related to intangible and aesthetic values. The environmental benefit of filtering air pollutants is also somewhat associated with this factor. This may be because air quality is less immediately perceptible than other physical benefits such as reduced noise and wind speed. People may also associate clean air with general ideas of positive environmental and natural quality, which might tend to tie it in with the more subjective benefits.

The third factor (physical benefits) accounts for $12.8 \%$ of the variance in responses and includes the more tangible, physical benefits of cooling the home in summer, reducing noise, and slowing wind speed along with the visual benefit of screening unwanted views. Screening may be associated with physical benefits because it is based on the tree's ability to block the view physically. Increased privacy, which clearly is related to screening, also falls into this group. Filtering air pollutants is also weakly associated with this factor.

The fourth factor (insects and exudation), which accounts for $7.2 \%$ of the variance in responses, includes three items relating to insects and to substances exuded or emitted by trees. It includes allergies, which are commonly attributed to pollen or other substances given off by trees. A possible explanation for the co-occurrence of allergies and insects on 
Table 3. Comparison of mean factor scores between Downers Grove and North Somerset/Torbay surveys.

\begin{tabular}{|c|c|c|c|c|c|c|}
\hline \multicolumn{7}{|c|}{ Factors } \\
\hline Survey & $\begin{array}{l}\text { 1.* General } \\
\text { annoyances }\end{array}$ & $\begin{array}{l}\text { 2. Intangible } \\
\text { benefits }\end{array}$ & $\begin{array}{c}\text { 3. }{ }^{*} \text { Physical } \\
\text { benefits }\end{array}$ & $\begin{array}{l}\text { 4. Insects and } \\
\text { exudation }\end{array}$ & $\begin{array}{l}\text { 5. Seasonal } \\
\text { aesthetics }\end{array}$ & 6.* Shade \\
\hline North Somerset/Torbay & 0.625 & 0.033 & 0.363 & 0.098 & 0.096 & -0.598 \\
\hline Downers Grove & -0.393 & -0.021 & -0.228 & -0.062 & -0.061 & -0.375 \\
\hline
\end{tabular}

*t-test for difference between North Somerset/Torbay and Downers Grove significant, $P<0.0001$.

this factor might be that some people blame tree flowers both for attracting insects and for causing pollen-related allergies. Insects and sap may be associated because sap attracts certain kinds of insects or perhaps because some people identify honeydew produced by insects as a type of sap.

The fifth factor (seasonal aesthetics) accounts for $4.8 \%$ of the variance and consists of the benefit of flowers on the tree together with the annoyance of flowers falling from the tree. It also includes a weaker association with autumn color. Both flowers and autumn color are seasonal effects related to visual aesthetics.

The sixth factor (shade) includes the benefit of shade plus a weaker association with cooling the home in summer, accounting for $4.6 \%$ of the variance.

\section{Effect of Benefits and Annoyances on Overall Opinion}

To see how the different groups of benefits and annoyances identified in the principal components analysis are related to residents' overall satisfaction with their street tree, we correlated factor scores from each of the six factors with respondents' ratings of overall opinion. Three factors have significant positive correlations with overall satisfaction. Factor 2 (intangible benefits) has by far the strongest correlation with overall opinion of any of the factors $(\mathrm{r}=0.495, P<0.0001)$. Factor 5 (seasonal aesthetics) has a somewhat smaller correlation ( $\mathrm{r}=0.217, P<0.0001$ ), whereas factor 3 (physical benefits) has a weak but significant positive influence on overall opinion $(\mathrm{r}=0.132, P<0.017$ ). Factor 1 (general annoyances) is the only factor to have a significant negative correlation with overall opinion $(\mathrm{r}=-0.119, P<0.032)$. The small size of this correlation suggests that, overall, the perceived annoyances of street trees do not have as great an influence on people's satisfaction with the tree as do the perceived benefits.

\section{Comparison of Factor Scores Between Downers Grove and North Somerset/Torbay}

Table 3 shows a comparison between factor scores from the Downers Grove and North Somerset/Torbay surveys. The respondents in the two surveys differ significantly on three of the six factors. In the North Somerset/Torbay survey, respondents rated the items associated with factor one (general annoyances) as substantially and significantly more annoying than did respondents in the Downers Grove survey. The re- spondents in the North Somerset/Torbay survey also rated the benefits associated with factor three (physical benefits) significantly higher than did those in the Downers Grove survey. On the other hand, factor six (shade) was rated substantially and significantly lower in the North Somerset/Torbay survey than in the Downers Grove survey.

\section{Shape, Size, and Growth Rate}

There was no significant difference between the North Somerset/Torbay and Downers Grove surveys in respondents' ratings of the attractiveness of their tree's shape. Almost $85 \%$ of respondents in both surveys found the shape of the tree outside their home to be at least "somewhat attractive" and over one-third found it to be "very attractive." There was, however, a decided difference between the Downers Grove and North Somerset/Torbay surveys in respondents' evaluations of the size and growth rate of the tree outside their home (Table 4). No respondents in the North Somerset/Torbay survey thought their tree was too small compared with $53 \%$ in the Downers Grove survey. Thirty-nine percent of respondents in the North Somerset/Torbay survey thought their tree was too large in contrast with less than $1 \%$ in the Downers Grove survey. A similar difference appeared when respondents stated their satisfaction with their tree's growth rate. No respondents in the North Somerset/Torbay survey thought the tree outside their home grew too slowly compared with approximately one-third in the Downers Grove survey. No respondents in the Downers Grove survey considered that the

\section{Table 4. Respondent opinion of tree size and growth} rate.

\begin{tabular}{cccccc}
\hline & \multicolumn{2}{c}{ North Somerset/Torbay } & & \multicolumn{2}{c}{ Downers Grove } \\
\cline { 2 - 3 } \cline { 5 - 6 } & $\mathrm{N}$ & $\%$ & & $\mathrm{~N}$ & $\%$ \\
\hline Size of tree* & & & & & \\
Too small & 0 & 61 & & 125 & 53 \\
Just right & 76 & 39 & & 2 & 1 \\
Too large & 48 & 0 & & 92 & 33 \\
Growth rate* & & & & 184 & 67 \\
Too slow & 0 & 73 & & 0 & 0 \\
Good rate & 74 & 27 & &
\end{tabular}

*Mann-Whitney U-test for difference between North Somerset/Torbay and Downers Grove significant, $P<0.0001$. 
tree outside their home grew too fast compared with $21 \%$ in the North Somerset/Torbay survey.

No measurements of actual tree size were recorded in the Downers Grove survey. Thus, it is not possible to directly compare the physical sizes of the trees being rated in the Downers Grove and the North Somerset/Torbay surveys. The Village Forester of Downers Grove at the time of the survey, however, noted that some of the trees that were included in the survey had been planted relatively recently and were not yet full grown. This raises the possibility that part of the difference between the Downers Grove and North Somerset/ Torbay surveys in evaluations of tree size and growth rate could simply be the result of differences in the ages of the trees respondents were evaluating and not to differences in their preferences for tree size and growth rate.

A comparison with ratings of tree size from a neighborhood tree survey reported by Schroeder and Ruffolo (1996), however, suggests that this is not the case. In that survey, which was done at the same time as the individual tree survey reported here, residents of selected neighborhoods in Downers Grove evaluated street trees in their whole neighborhood, not just the one in front of their house. One of these neighborhoods had a single-species, even-aged population of mature silver maples (Acer saccharinum) that formed an arching canopy over the street. On a scale of 1 (too small) to 3 (too large), this neighborhood had an average tree size rating of 2.00 , indicating that the residents thought these large, mature trees were "just right" in size. The average tree size rating of 2.39 from the North Somerset/Torbay survey was significantly higher $(\mathrm{F}[2,603]=141.05, P<0.0001)$, indicating that, on average, the respondents thought their trees were somewhat too large, although most of their trees were probably physically smaller than the mature silver maples in Downers Grove. Thus, it appears likely that there is a real difference in preferences for tree size with the respondents in the North Somerset/Torbay survey preferring their trees to be smaller than did the respondents in the Downers Grove survey.

\section{DISCUSSION}

The findings show that residents in all the communities surveyed held similarly high levels of overall satisfaction with the trees outside their homes. Benefits generally outweighed the annoyances caused by street trees, and overall satisfaction was more strongly related to the intangible benefits of trees than to their physical benefits or annoyances.

A number of significant differences were found between the respondents in the Downers Grove and North Somerset/ Torbay surveys. Residents of North Somerset/Torbay evaluated all annoyances as more serious than did the Downers Grove respondents. North Somerset/Torbay respondents rated most physical benefits as significantly more important than the Downers Grove respondents but considered shade to be less important as a benefit of their trees. Respondents in the North Somerset/Torbay survey appeared to prefer smaller trees and trees with slower growth rates than did the residents of Downers Grove.

There are several possible explanations for the observed differences in attitudes between respondents in the Downers Grove and North Somerset/Torbay surveys. One possibility is that some differences, particularly regarding intangible benefits, may be the result of cultural differences between the communities. For example, in the North Somerset/Torbay survey, the benefits of "brings nature closer" and "provides spiritual values" were rated significantly higher than in the Downers Grove survey, whereas in the Downers Grove survey, "increases sense of community" and "increases sense of home and family" were rated significantly higher. This suggests that there may be different underlying values influencing residents' evaluations of trees. Whether this stems from cultural differences and whether such differences, if they exist, operate at the community, regional, or national level cannot be determined from our data. Nevertheless, this result suggests that further research to investigate the possible role of culture in tree attitudes might be worth pursuing.

Another explanation for differences, particularly in ratings for tree shade, has to do with the differing climates between the regions where the surveys were done. The Downers Grove survey was done in a midwestern U.S. community, where summers can be very hot and shade is greatly appreciated for shelter from the midday sun. The mean daily maximum temperature in Chicago, the nearest large city to Downers Grove, is $28.7^{\circ} \mathrm{C}\left(83.7^{\circ} \mathrm{F}\right)$ compared with $22.3^{\circ} \mathrm{C}\left(72.1^{\circ} \mathrm{F}\right)$ in London (World Meteorological Organization 2006). The United Kingdom, on the other hand, experiences lower levels of solar radiation combined with high levels of rainfall, leading residents to value direct sunshine quite highly. London experiences an average of 145 days of precipitation per year compared with 94 for Chicago (World Meteorological Organization 2006). In such a cool, cloudy climate, trees that cause shade may be considered an annoyance rather than a benefit.

Differences in the spatial layout of residential properties may also be a factor contributing to differences in evaluations of certain benefits and annoyances of street trees. Less physical space relative to population means that properties and the associated infrastructure in UK communities tend to be arranged closer together. In the United States, which is generally less densely populated than the United Kingdom, suburbs are more spread out with larger lots, resulting in street trees growing further away from the home.

Figures 1 and 2 illustrate the differences in street layout between the communities in these surveys. Trees on the North Somerset/Torbay properties generally grow closer to property boundaries and to the actual building itself. Such close proximity between tree and building is likely to increase the impact on residents of annoying tree attributes such as 
falling debris and root damage while simultaneously increasing advantages gained from physical benefits such as slowing wind speed. The relative proximity of trees to North Somerset/Torbay residences also would result in more shade cast over the home compared with Downers Grove, exacerbating the effect of climate noted here.

Proximity of trees to houses in combination with a cooler, cloudier climate could also explain the preference for smaller tree size and slower growth rates in North Somerset and Torbay. Smaller, slower growing trees are less likely to physically dominate homes and therefore keep annoyances to a minimum. Downers Grove residents by contrast would prefer larger trees that provide more shade and which, being farther away, would not tend to dominate the home so much.

Increasing age of the home owner can have a negative impact on opinions toward trees. Sommer et al. (1989) reported that opinions of trees within their study did not relate to any demographic variable except for age, in which older householders had a lower opinion of trees than younger residents. Flannigan (2005) also found a significant correlation between increasing age and negative opinions of trees. In our surveys, North Somerset and Torbay respondents tended to be older than those in Downers Grove, which could be another explanation for their higher ratings of annoyances.

Differences in species and management practices between Downers Grove and North Somerset/Torbay must also be considered as a possible source of variation in responses to benefits and annoyances. The three communities all had different combinations of tree species, and the practice of pollarding, which was commonplace in North Somerset and Torbay, did not occur at all in Downers Grove. Pollarding has a significant impact on the appearance of a tree and may tend to obscure the visual distinctions between the natural forms of species. It was not possible to compare ratings of individual species across communities in this data set, but the fact that ratings of overall satisfaction and the trees' visual appearance were very similar across communities suggests that the visual appearance of "urban nature" is a valued component of urban life irrespective of variations in size, pruning practices, and species-specific characteristics.

A final factor that might also have contributed to the differences in responses is the survey sampling procedure, which varied depending on the needs and interests of the local tree manager and researcher. In particular, one group of respondents in Torbay was specifically chosen to learn about residents who the local arborist thought disliked their trees. This sampling strategy would seem to increase the likelihood that the North Somerset/Torbay survey respondents would have more negative attitudes toward trees than their Downers Grove counterparts. In fact, however, the Torbay residents who were selected because of their supposed dislike of trees did not have significantly lower ratings of overall opinion than the other respondents, and their ratings of most annoyances were not consistently higher than in the other communities.

Finding that residents in geographically and culturally diverse communities held equally strong positive opinions about the trees outside their home is consistent with theories that appreciation of vegetation is an inherited consequence of human evolution (Heerwagen and Orians 1993). Another possible explanation, however, is that most inhabitants in these surveys actively chose to purchase a property with a street tree directly outside their home (and likely with trees in front of neighboring properties as well), and therefore both survey samples could be considered biased toward people who like street trees. Such a self-selection factor among residents could help explain the consistently high overall satisfaction with trees across such a disparate group of tree species and management regimes.

\section{CONCLUSIONS}

Our survey results do not lend support to the view that UK residents consistently have negative attitudes toward trees in front of their houses. If that were the case, then the respondents in the North Somerset/Torbay survey would be expected to give lower ratings to their trees than the Downers Grove respondents. In fact, respondents from all three communities had equally positive overall opinions of their street trees, although they did differ somewhat in their evaluations of particular benefits, annoyances, and attributes of the trees. We believe that the most prominent of these differences are related to variations in climate, the layout and size of properties, and the proximity of trees to houses. Possibly as a result of a cooler, cloudier climate and closer proximity of trees to houses and gardens, respondents in the North Somerset/Torbay survey preferred smaller trees, did not regard shade as a major benefit, and were more aware of annoyances related to the physical size and proximity of the tree. However, these annoyances did not result in lower overall satisfaction with trees in North Somerset/Torbay than in Downers Grove. Intangible and aesthetic benefits appeared to predominate in giving rise to high overall opinions of street trees, despite whatever annoyances the trees caused.

Arborists in both the United Kingdom and the United States should be aware that local conditions of climate and spatial layout of streets and homes may affect the impact that various benefits and annoyances have on home owners and should take this into account when selecting species and locations for planting trees. At the same time, they should not assume that complaints about particular problems with trees imply a generally negative attitude toward street trees among the populace. Community surveys such as the ones used in this research provide a way for arborists to obtain a more complete understanding of people's attitudes toward trees. The analyses reported in this article show that the methodol- 
ogy of Sommer et al. (1990) can be adapted to study how attitudes toward trees vary across communities in different countries. In the future, more focused multinational studies, with a closer match among tree sizes, tree species, management techniques, and spatial layout of the street, could help determine how attitudes vary between cultures and climatic zones. Further comparisons between communities within a region could show how attitudes toward trees are influenced by local factors such as available building space, neighborhood age, and urban planning policies. This kind of knowledge could help urban foresters and arborists to tailor tree management to the particular needs and desires of the local community.

\section{LITERATURE CITED}

Anon. 1990. Town \& Country Planning Act, sections 198-210. Her Majesty's Stationery Officer, London, UK.

_ 2003. Solihull Urban Tree Strategy. Solihull Urban Metropolitan Council, Solihull, UK.

Baker, R. (Ed.). 1984. Proceedings of Seminars on Trees \& Planning. Polytechnic of the South Bank, Paper No. PCP 17. London, UK.

Clouston, B., and K. Stansfield (Eds.). 1981. Trees in Towns: Maintenance and Management. Architectural Press, London, UK.

Coles, R., and M. Caserio. 2004. Understanding and facilitating the social outputs of urban green spaces. Open Space: People Space, An International Conference on Inclusive Outdoor Environments. Edinburgh, UK.

Daily Mirror. 2004. Call the Copse over Phantom Gardener. Wednesday, February 4. http://www.mirror.co.uk/news/ topstories/tm_objectid $=13911869 \% 26 \mathrm{method}=$ full\%26siteid = 94762-name_page.html (accessed 7/27/05).

DEFRA (Department for Environment Food and Rural Affairs). 2002. Survey of Public Attitudes to Quality of Life and to the Environment-2001. Press Release accessed from http://www.defra.gov.uk/news/2002/021009c.htm (accessed 6/21/05).

Dobson, M., and D. Patch. 1997. Trees in dispute. Arboricultural Practice, Note 3. Arboricultural Advisory and Information Service, Farnham, UK.

Flannigan, J. 2005. An evaluation of residents' attitudes to street trees in southwest England. Arboricultural Journal 28:219-241.

Fraser, E.D., and W.A. Kenney. 2000. Cultural background and landscape history as factors affecting perceptions of the urban forest. Journal of Arboriculture 26:107-113.

Hays, W.L. 1973. Statistics for the Social Sciences. Holt, Rinehart and Winston, New York, NY.

Heerwagen, J.H., and G.H. Orians. 1993. Humans, habitats and aesthetics, pp. 142-146. In The Biophilia Hypothesis Kellert, S.R., and E.O. Wilson, Eds. Island Press, Washington, DC.
Hitchmough, J.D., and A.M. Bonugli. 1997. Attitudes of residents of a medium sized town in southwest Scotland to street trees. Landscape Research. 22:327-337.

Horticulture Week. 1994. Volume 215, No. 11 (March 17). Haymarket Trade \& Leisure Magazines.

Jackson, J.E. 1991. A User's Guide to Principal Components. Wiley, New York, NY.

Kaiser, H.F. 1960. The application of electronic computers to factor analysis. Educational and Psychological Measurement 20:141-151.

Kalmbach, K.L., and J.J. Kielbaso. 1979. Residents' attitudes toward selected characteristics of street tree plantings. Journal of Arboriculture 5:124-129.

Kaplan, K., and S. Kaplan. 1989. The Experience of Nature: A Psychological Perspective. Cambridge University Press, Cambridge, UK.

O'Brien, L., and J. Claridge (Eds.). 2002. Trees are Company: Social Science Research Into Woodlands and the Natural Environment. Forestry Commission, Edinburgh, UK.

Riseley, T.F. 1969. Street trees-liabilities or assets. Arboricultural Journal. 1:194-198.

Schroeder, H.W., and W.N. Cannon Jr. 1983. The esthetic contribution of trees to residential streets in Ohio towns. Journal of Arboriculture 9:237-243.

Schroeder, H.W., and S.R. Ruffolo. 1996. Householder evaluations of street trees in a Chicago suburb. Journal of Arboriculture 22:35-43.

Sheets, V.L., and C.D. Manzer. 1991. Affect, cognition and urban vegetation: some effects of adding trees along city streets. Environment and Behavior 23:285-304.

Sommer, R. 1997. Further cross national studies of tree form preference. Ecological Psychology 9:153-160.

Sommer, R., P.A. Barker, H. Guenther, and K. Kurani. 1989. Householder evaluation of two street tree species. Journal of Arboriculture 15:99-103.

Sommer, R., H. Guenther, and P.A. Barker. 1990. Surveying householder response to street trees. Landscape Journal 9:79-85.

Sommer, R., H. Guenther, P.A. Barker, and J.P. Swenson. 1993a. Comparison of four methods of street tree assessment. Journal of Arboriculture 19:27-34.

Sommer, R., and B.A. Sommer. 1989. The factor structure of street tree attributes. Journal of Arboriculture 15:243-246.

Sommer, R., and J. Summit. 1995. An exploratory study of preferred tree form. Environment and Behavior 27: 540-557.

1996. Cross national rankings of tree shape. Ecological Psychology 8:327-341.

Sommer, R., J. Summit, and A. Clements. 1993b. Slide ratings of street tree attributes: Some methodological issues and answers. Landscape Journal 12:17-22. 
Summit, J., and R. Sommer. 1999. Further studies of preferred tree shapes. Environment and Behavior 31: 550-576.

Williams, K. 2002. Exploring resident preferences for street trees in Melbourne, Australia. Journal of Arboriculture 28:161-170.

World Meteorological Organization. 2006. http://www. wmo.ch/index-en.html (accessed 1/10/06).

Herbert Schroeder (corresponding author)

Research Social Scientist

USDA Forest Service

North Central Research Station

1033 University Place, Suite 360

Evanston, IL 60201, U.S.

hschroeder@fs.fed.us

\section{John Flannigan}

Trees Officer

Streets \& Open Spaces

North Somerset Council

Weston Court, Oldmixon Crescent

Weston super Mare, BS24 9AU, UK

\section{Richard Coles}

Professor

School of Architecture

Birmingham Institute of Art \& Design

University of Central England

Birmingham, B7 4DX, UK

Zusammenfassung. Die Erforschung der Anwohnergewohnheiten hat gezeigt, dass Straßenbäume als hochwertige Elemente in der urbanen Umgebung angesehen werden, und dass ihre Vorteile weit über die Nachteile überwiegen. In den amerikanischen Gemeinden wurde viel in dieser Richtung geforscht, und es bleibt unsicher, ob diese Ergebnisse generalisiert und auf andere Gemeinden oder Länder zu übertragen sind. Wir verglichen die Meinungen der Anwohner zu Straßenbäumen, Wahrnehmung der Vor- und Nachteile der Bäume und Präferenzen für Baumgröße, Form und Wachstumsrate in drei Gemeinden in den USA und Großbritannien. Die allgemeine Einstellung zu nahen Straßenbäumen war positiv und unterschied sich nicht zwischen den zwei Gemeinden in Großbritannien und der US-Gemeinde. Die Teilnehmer der englischen Gemeinde bewerteten die Nachteile stärker, Schatten eher als Nachteil und die physikalischen Vorteile deutlicher als die Amerikaner. Die Teilnehmer der zwei englischen Gemeinden bevorzugten eher kleine Bäume mit langsamen Wachstumsraten. Obwohl die Vergleiche nicht genutzt werden können, um Rückschlüsse auf die Unterschiede in ganz Großbritannien und den USA zu ziehen, so geben sie doch einige spezifische Hinweise auf welche Weise die Charakteristika der Gemeinden, so wie Klima und Nähe der Bäume zu Häusern zu Variationen bei der Einstellung gegenüber Bäumen beitragen können.

Resumen. La investigación sobre las actitudes de los residentes ha mostrado que los árboles son elementos del ambiente urbano altamente valorados y que sus beneficios pesan más que sus molestias. Mucha de esta investigación fue hecha en los Estados Unidos, y no podría ciertamente ser generalizada a otras comunidades o países. Se compararon las opiniones de los residentes de calles arboladas, las percepciones de los beneficios y molestias que dan los árboles, y las preferencias por tamaño del árbol, forma y tasa de crecimiento entre tres comunidades en los Estados Unidos y Reino Unido. En todas partes las opiniones fueron positivas y no hubo diferencias entres las comunidades de los dos países. Los encuestados en las comunidades del Reino Unido indicaron las molestias como más serios, sombra como el menor de los beneficios, y beneficios físicos como los más significativos, que los residentes de las comunidades de los Estados Unidos. Los encuestados en las dos comunidades del Reino Unido también prefirieron árboles más pequeños que árboles grandes. A pesar de que estas comparaciones no pueden ser usadas para hacer diferencias en todo Estados Unidos y Reino Unido, ellas sugieren ciertas formas específicas en las cuales las características de las comunidades, tales como el clima y la proximidad de los árboles a las casas, pueden contribuir a la variación de actitudes hacia los árboles. 